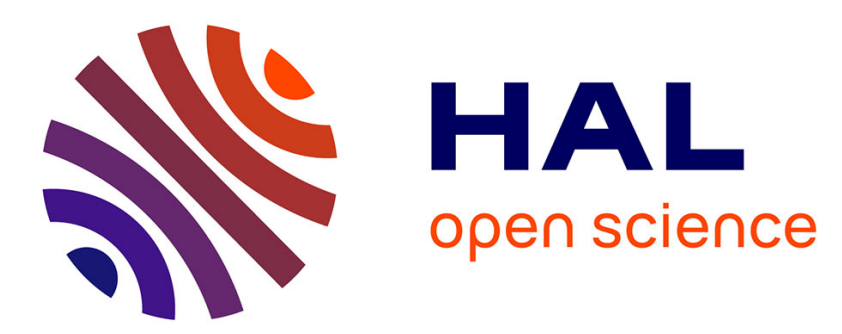

\title{
Solvent as a competitive inhibitor for Candida antarctica lipase B
}

\author{
Marianne Graber, Romain Irague, Eric Rosenfeld, Sylvain Lamare, Linda \\ Franson, Karl Hult
}

\section{> To cite this version:}

Marianne Graber, Romain Irague, Eric Rosenfeld, Sylvain Lamare, Linda Franson, et al.. Solvent as a competitive inhibitor for Candida antarctica lipase B. Biochimica et Biophysica Acta Proteins and Proteomics, 2007, 1774, pp.1052-1057. hal-00329734

\section{HAL Id: hal-00329734 \\ https://hal.science/hal-00329734}

Submitted on 13 Oct 2008

HAL is a multi-disciplinary open access archive for the deposit and dissemination of scientific research documents, whether they are published or not. The documents may come from teaching and research institutions in France or abroad, or from public or private research centers.
L'archive ouverte pluridisciplinaire $\mathbf{H A L}$, est destinée au dépôt et à la diffusion de documents scientifiques de niveau recherche, publiés ou non, émanant des établissements d'enseignement et de recherche français ou étrangers, des laboratoires publics ou privés. 


\section{Solvent as a competitive inhibitor for Candida antarctica}

\section{lipase B}

Marianne Graber ${ }^{1} *$, Romain Irague ${ }^{1}$, Eric Rosenfeld ${ }^{1}$, Sylvain Lamare $^{1}$, Linda Franson $^{2}$ and Karl Hult ${ }^{2 *}$

${ }^{1}$ Université de la Rochelle, Laboratoire de Biotechnologies et Chimie Bio-organique, Pôle Sciences et Technologies, Bâtiment Marie Curie, Avenue Michel Crépeau, 17042 La Rochelle, Cedex 1, France

${ }^{2}$ Department of Biochemistry, School of Biotechnology, Royal Institute of Technology, AlbaNova University Center, SE-106 91 Stockholm, Sweden. Phone: + 46855378364 Fax: +46855378468, email: kalle@biotech.kth.se

Foot note : * Corresponding authors : Tel.: 33-5-4645-8630; fax: 33-5-46-45-82-65. E-mail address: mgraber@univ-lr.fr (M. Graber) and fax: 46-8-5537-8468. E-mail address: kalle@biotech.kth.se (K. Hult)

\section{Keywords}

kinetics - organic solvent - molecular modeling - solid/gas biocatalysis - conformational change - solubility 


\section{SUMMARY}

In enzyme-catalysed reactions, the choice of solvent often has a marked effect on the reaction outcome. In this paper, it is shown that solvent effects could be explained by the ability of the solvent to act as a competitive inhibitor to the substrate.

Experimentally, the effect of six solvents, 2-pentanone, 3-pentanone, 2-methyl-2-pentanol, 3methyl-3-pentanol, 2-methylpentane and 3-methylpentane was studied in a solid/gas reactor. As a model reaction, the CALB- catalyzed transacylation between methyl propanoate and 1propanol, was studied. It was shown that both ketones inhibited the enzyme activity whereas the tertiary alcohols and the hydrocarbons did not. Alcohol inhibition constants, $\mathrm{K}_{\mathrm{i}}$, determined in presence of 2-pentanone, 3-pentanone, and 3-methyl-3-pentanol, confirmed the marked inhibitory character of the ketones and an absence of inhibition of 3-methyl-3pentanol.

The molecular modeling study was performed on three solvents, 2-pentanone, 2-methyl-2pentanol and 2-methyl pentane. It showed a clear inhibitory effect for the ketone and the tertiary alcohol, but no effect for the hydrocarbon. No change in enzyme conformation was seen during the simulations.

The study led to the conclusion that the effect of added organic component on lipase catalyzed transacylation could be explained by the competitive inhibitory character of solvents towards the first binding substrate methyl propionate. 


\section{Introduction}

For a large number of enzymes, and especially for some lipases showing substantial activity in nearly anhydrous solvents, the use of organic solvents as reaction medium possesses great advantages. Those advantages include solubility of hydrophobic substrates, increased thermostability of the enzyme, and a shift of the thermodynamic equilibrium in favour of synthesis over hydrolysis. The enzymatic activity in organic solvents varies significantly with the solvent used, but unfortunately it is often lower than in water solutions. Therefore it is important to make a good choice of solvent. Several studies performed in liquid organic media have been devoted to the role of solvent the last decades [1-8], but still there is no general understanding of the solvent effects seen. The suggested origins of solvent effects can be divided into three main categories:

1. Change in enzyme conformation and/or flexibility. The conformation and flexibility of an enzyme are crucial for efficient catalysis. A proper choice of solvent will optimize these parameters for a specific reaction. The suggestion has been investigated several times with different outcomes (authors agreeing; [9] and [10], authors disagreeing; [11] and [12]).

2. Changes in solubility and desolvation of substrates and products. A change of solvent will affect the solubility and desolvation of substrates, products, and enzyme, leading to a changed common equilibria for all participant species. This will change the apparent substrate preference of the enzyme without changing the intrinsic properties of the reaction. Solubility effects are often expressed as a relation between enzyme activity and $\log \mathrm{P}$ of the solvent [8]. 
3. Competitive inhibition. Solvent molecules binds into the active site, where they will act as competitive inhibitors to the substrate. Different kinds of solvent molecules have different ability to bind to a given active site, and this difference causes solvent effects [13-14].

Solvent effects are difficult to assess in liquid media, since the thermodynamic activities of substrates, products, and solvents can not be varied individually. There will also be a concomitant changes in substrate and product solubility with solvent, and the correction for such changes is far from straightforward. These limitations can be overcome using a solid/gas reactor. In a solid/gas reactor it is possible to control, and independently adjust, the thermodynamic activities of substrates and non-reactants around the enzyme, so that a single reaction parameter can be changed without affecting any others [15-16]. Thus, when using a solvent/gas reactor, all thermodynamic activities will be constant during a reaction, and there will be no effects related to changes in substrate solubility.

In this study, we evaluated solvent competitive inhibition as an explanation of solvent effects. Experimental data from a solid/gas reactor, assuring the absence of solvent effects, was combined with molecular modeling studies, and CALB- catalyzed transacylation between methyl propanoate and 1-propanol was used as a model system. The study included six organic solvents (2-pentanone, 3-pentanone, 2-methyl-2-pentanol, 3-methyl-3-pentanol, 2methylpentane and 3-methylpentane) of roughly the same molecular size, but with different functional groups. 


\section{Materials and Methods}

\section{Enzyme and chemicals}

Chirazyme L2 (lyophilized lipase from Candida antarctica type B) was a gift from Roche Industrie (Penzberg, Germany). All substrates were of the highest purity (99\% minimum).

Chemicals were dried prior to use. 1-Propanol was dried by refluxing with magnesium and then distilled. Methyl propanoate was dried with $\mathrm{Na}_{2} \mathrm{CO}_{3}$ and distilled from $\mathrm{P}_{2} \mathrm{O}_{5}$. The dried solvents were stored under argon atmosphere and over molecular sieves.

\section{Adsorption of lipase onto a solid support}

Enzyme adsorption was performed onto Chromosorb P AW DMCS, mesh 60-80 (Acid Washed DiMethylChloroSilane) (Prolabo, France) as described in a previous work [17] by using $30 \mathrm{mg}$ of lyophilized enzyme preparation per $6 \mathrm{~g}$ of solid support Chromosorb.

\section{Experimental setup for solid/gas catalysis}

The bioreactor used in this study is described in previous publications [15,18]. A typical experiment was run at $70^{\circ} \mathrm{C}$, with about $15 \mathrm{mg}$ of adsorbed enzyme, $1 \mathrm{mg}$ of adsorbed enzyme preparation corresponding to $5 \mu \mathrm{g}$ of lyophilized lipase. The total flow passing through the

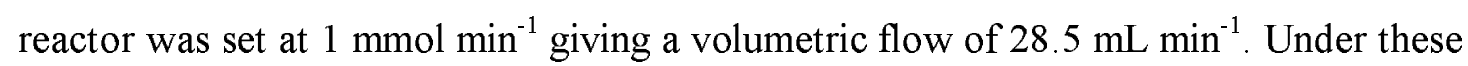
conditions, less than $20 \%$ of the substrates were converted to products allowing the assumption that initial rates (expressed in $\mu$ moles of product formed per minute and per $\mathrm{mg}$ of enzymatic preparation) were measured and that inhibition by the products could be neglected. 


\section{Chromatographic assays}

The vapour phase leaving the bioreactor was sampled using a $0.25 \mathrm{~mL}$ loop on a six-way valve (Valco) maintained at $150^{\circ} \mathrm{C}$. Samples were automatically injected in the split injector of a gas chromatograph (Agilent model 6890N) equipped with a flame ionization detector (FID) for detection of all products. For the experiments in presence of 2-pentanone, 3-pentanone, 3methylpentane, 2-methyl-2-pentanol and 3-methyl-3-pentanol, the column used was an OV 01 ( $28 \mathrm{~m} \times 0.32 \mathrm{~mm}$ i.d. $\times 0.5 \mu \mathrm{m}$ film thickness, Chrompack, France). For the experiments in presence of 2-methylpentane, a DB 1701 column was used (30 m x $0.32 \mathrm{~mm}$ i.d. x $0.25 \mu \mathrm{m}$ film thickness, JW Scientific). In all cases the split ratio was 196:1. The injector and the detector were kept at $220^{\circ} \mathrm{C}$ and $250^{\circ} \mathrm{C}$ respectively. Nitrogen was used as a carrier gas with a flow rate of $1.1 \mathrm{~mL} \mathrm{~min}^{-1}$ in the column. Hydrogen and air were supplied to the FID at 35 and $350 \mathrm{~mL} \mathrm{~min}^{-1}$, respectively.

For the quantification of methanol, propanol, methyl propanoate and propyl propionate, in the presence of 2-pentanone and 3-pentanone, the initial column temperature was $40^{\circ} \mathrm{C}$. The temperature was kept at $40^{\circ} \mathrm{C}$ during 2 minutes and then increased to $45^{\circ} \mathrm{C}$ using a rate of $0.5^{\circ} \mathrm{C} \mathrm{min}^{-1}$. For the quantification of the substrates and products, in the presence of 3 methylpentane, the column temperature was held at $40^{\circ} \mathrm{C}$ for $2 \mathrm{~min}$, then programmed to increase at $0.1^{\circ} \mathrm{C} \cdot \mathrm{min}^{-1}$ to $41^{\circ} \mathrm{C}$. For the quantification of the substrates and products, in the presence of 2-methylpentane, the column temperature was held at $60^{\circ} \mathrm{C}$ for $1 \mathrm{~min}$, then programmed to increase at $1^{\circ} \mathrm{C} \cdot \min ^{-1}$ to $73^{\circ} \mathrm{C}$. Quantitative data were obtained after integration on an AGILENT 3396 series III integrator. An external standard method was used for the calculations. 


\section{Molecular modeling}

All modeling was done on a SGI fuel station (Silicon Graphics Inc) using the Sybyl 7.0 [19] package (Tripos Inc). For the molecular dynamics simulations, the Kollman All Atom [20,21] force field was used. A crystal structure of the empty enzyme, PDB code 1TCA [22] was retrieved from RCSB data bank [23], and prepared for further modeling as previously described [24].

For each solvent, a solvent molecule was manually modelled into the active site in a conformation utilizing available hydrogen bonding possibilities. The manually found position was optimized by a series of short dynamics simulations and energy minimizations; followed by an energy minimization of whole structure. Finally a dynamics simulation (130 ps) was ran on the whole structure, starting with a 30 ps warm-up phase. The dynamics simulation was sampled every $250 \mathrm{ps}$, giving 400 snapshot structures of the enzyme-solvent complex. The whole procedure was then independently repeated from the solvent docking phase, giving a total of 800 snapshot structures. All snapshot structures were superimposed on the first one using all enzyme atoms, and the resulting file was used to visualize the solvent molecule motion in the active site during the molecular dynamics simulation.

\section{Results}

Lipase-catalyzed transacylation reactions follow a ping-pong mechanism with an alcohol dead-end inhibition $[14,17,25]$. In the present case (Scheme 1) the lipase can bind either methyl propanoate yielding a lipase-methyl propanoate complex or bind 1-propanol yielding an unproductive enzyme-propanol dead-end complex. The lipase-methyl propanoate complex 
can proceed to an acyl-enzyme intermediate and the first product (methanol) would be released. Next, the second substrate, propanol, interacts with the acyl-enzyme resulting in the the product propyl propanoate and a free lipase. In the present investigation, the ping-pong mechanism was confirmed in the presence of 2-pentanone, 3-pentanone and 3-methyl-3pentanol, all at a fixed thermodynamic activity of 0.37 . As an example, the results obtained in presence of 2-pentanone are shown in Figure 2.

\section{Study of the effect of different organic compounds on CALB activity by gaseous phase}

\section{biocatalysis experiments}

Enzyme on a solid support was placed in the solid/gas bioreactor, and was percolated with nitrogen carrying the two substrates methyl propanoate and 1-propanol, whose thermodynamic activities were kept constant (0.15). In addition, a non reactant organic component mimicking a solvent was added, with thermodynamic activities between 0 and 0.6 . In Figure 1 the transacylation activity of CALB is shown in the presence of gradually increasing thermodynamic activities of 2-pentanone, 3-pentanone, 2-methyl-2-butanol, 2methyl-2-pentanol, 3-methyl-3-pentanol, 2-methylpentane and 3-methylpentane. The two ketones and 2-methyl-2-butanol clearly inhibited the enzyme activity, since the initial reaction rate decreased with an increasing ketone thermodynamic activity. For the other substrates, no inhibition was seen.

\section{Determination of inhibition constants of propanol, $K_{i}$, in presence of 2-pentanone, 3-}

\section{pentanone and 3-methyl-3-pentanol}

In the presence of a solvent, both the apparent $V_{\max }$ and propanol inhibition constants $\mathrm{K}_{\mathrm{i}}$ can be determined from experimental data, where the reaction initial rate, $v_{i}$, is plotted versus the thermodynamic activity of methyl propanoate $\mathrm{a}_{\mathrm{MP}}$, at several fixed thermodynamic activities of 
propanol $\mathrm{a}_{\mathrm{P}}$ (Fig 2). Replotting the data onto reciprocal axes, $1 / \mathrm{v}_{\mathrm{i}}$ versus $1 / \mathrm{a}_{\mathrm{MP}}$ (Fig 3 ) yielded a graph with straight lines intersecting at $1 / a_{M P}=1$, and the value of the ordinate at this intersection point equals $1 / \mathrm{V}_{\max }$. From the reciprocal plot, dissociation constants, $\mathrm{K}_{\mathrm{i}}$, of propanol in the presence of 2-pentanone can be obtained. When the slopes of the converging lines in the reciprocal plot is plotted against the thermodynamic activity of propanol, $a_{p}$, the result is a straight line whose intersection with the abscissa equals $-K_{i}$ (Fig 4).

With a fixed solvent activity of 0.37 , the dissociation constants for 2-pentanone, 3-pentanone and 3-methyl-3-pentanol were determined to $0.043 \pm 0.011,0.048 \pm 0.009$ and $0.02 \pm 0.012$, respectively. These values were in accordance with the varying inhibitory character of the different compounds. As a comparison, the $K_{I}$ obtained in absence of any added non- reactant component in the gaseous stream was found to be equal to 0.019 [17]. The $K_{I}$ obtained in the presence of the two ketones were about twice as high, indicating a competition between the ketones and propanol for the interaction with lipase active site. These values obtained for ketones are near to the previously determined $K_{I}$ obtained in the presence of 2-methyl-2butanol (equal to 0.045), which was found to be an inhibitor of CALB [25].

\section{Molecular modeling}

Interactions between the lipase and the solvents 2-pentanone, 2-methyl-2-pentanol, and 2methyl pentane were studied with molecular modeling. The ketone and the tertiary alcohol showed a clear affinity for the active site (Fig 5a - c). During a 100 ps simulation, both stayed in the active site bound with hydrogen bonds to the oxyanion hole and/or the catalytic serine. In the end of the simulation, the ketone lost its hydrogen bonds and started exploring the active site, but without leaving it. On the other hand, the alkane 2-methyl pentane (Fig 5d) initially 
started to move around thereafter left the active site. The enzyme structure did not show any significant conformational change during any of the dynamics simulations (results not shown).

\section{Discussion}

\section{Basis for solvent effects}

Experiments in a solid/gas reactor showed that the activity of CALB varied with solvent present in gas phase, and we have evaluated the possibility of the solvents as being competitive inhibitors to the substrate. The inhibitory effect of ketones was clearly demonstrated by increasing their thermodynamic activities (Fig 1). Their inhibitory effect was related to the effect on the dissociation constant of propanol, $K_{I}$, in the propanol-enzyme complex. An increase in $K_{I}$ means that the inhibition by propanol was lowered, or that the ketones took over the role as dead end inhibitors now competing with methyl propanoate to bind to the free enzyme. In previous studies the same behaviour was found for water and the moderately polar compound 2-methyl-2-butanol (Fig 1) $[18,25]$. Due to the similarity between the tertiary alcohols 2-methyl-2-butanol and 2-methyl-2-pentanol it could be assumed that they would exhibit a similar interaction with the enzyme, not equivalent to the experimental findings.

The experimental findings of an inhibitory effect of ketones and tertiary alcohols but not of alkanes on CALB-catalyzed reactions were supported by modeling results. 2-Pentanone and 2methyl-2-pentanol were both able to bind in the active site preventing methyl propanoate to react. On the other hand, 2-methyl pentane had no such effect. During molecular dynamics after being put in the active site, it started moving and finally left the active site, lacking the possibility getting anchored by hydrogen bonds. 
The experimental data in combination with molecular modeling results strongly supports competitive inhibition as an explanation for solvent effects. From a molecular modeling point of view, this study also presents two reasons for preferring "solvent inhibition" over "enzyme conformational change" as a basis for the solvent effects seen. Firstly and in favour of the hypothesis of competitive inhibition, experimentally known inhibitory solvents preferred to stay in the active site during the molecular dynamics simulations, whereas the non-inhibitory solvent had no urge to stay. Secondly, and in conflict with the suggestion of conformational changes, no significant enzyme conformational changes were seen in any of the simulations.

Solvent effects are complicated in nature, and the conclusion of this study relies on the use of the solid/gas reactor, giving the opportunity to exclude substrate solubility issues as a complicating factor. In liquid phase there is no such possibility, making it even harder measuring and understanding solvent effects. In summary, the three basic explanations for solvent effects mentioned in this paper - conformational change, solubility and competitive inhibition - will still be valid, and should all be considered when making efforts to explain experimentally achieved solvent effects in other systems.

\section{Acknowledgements}

Erik Vernet is acknowledged for his contributions to the modeling. 


\section{References}

[1] G. Bell, P.J. Halling, B.D. Moore, J. Partridge and D.G. Rees, Biocatalyst behaviour in low-water systems, Trends Biotechnol. 13 (1995) 468-473.

[2] J.S. Dordick, Principles and selected applications of non-aqueous enzymology, in: H.W. Blanch, D.S. Clark (Eds.), Applied biocatalysis, Marcel Dekker, New York, 1991, pp.1-51.

[3] C. Laane, S. Boeren, K. Vos and C. Veeger, Rules for optimization of biocatalysis in organic solvents, Biotechnol. Bioeng. 30 (1987) 81-87.

[4] R.H. Valivety, G.A. Johnston, C.J. Suckling and P.J. Halling, Solvent effects on biocatalysis in organic systems, equilibrium position and rates of lipase catalyzed esterification, BiotechnoL Bioeng. 38 (1991) 1137-1143.

[5] P.A. Fitzpatrick and A.M. Klibanov, How can the solvent affect enzyme enantioselectivity? J. Am. Chem. Soc. 113 (1991) 3166-3171.

[6] C. R. Wescott, A. M. Klibanov, The solvent dependence of enzyme specificity, Biochim. Biophys. Acta, 1206 (1994) 1-9.

[7] P. J. Halling, Biocatalysis in low-water media: understanding effects of reaction conditions, Curr. Opin. Chem. Biol. 4 (2000) 74-80. 
[8] A. K. Chaudhary, S. V. Kamat, E. J. Beckman, D. Nurok, R. M. Kleyle, P. Hajdu, A. J.

Russel, Control of subtilisin substrate specificity by solvent engineering in organic solvents and supercritical fluoroform, J. Am. Chem. Soc. 118 (1996) 12891-12901.

[9] K. Watanabe, T. Yoshida, S. Ueji, The role of conformational flexibility of enzymes in the discrimination between amino acid and ester substrates for the subtilisin-catalysed reaction in organic solvents, Bioorganic Chemistry, 32 (2004) 504-515.

[10] L. Olofsson, I. A. Nicholls, S. Wikman, TBADH activity in water-miscible organic solvents: correlations between enzyme performance, enantioselectivity and protein structure through spectroscopic studies, Org. Biomol. Chem. 3 (2005) 750-755.

[11] L. Yang, J. S. Dordick, S. Garde, Hydration of enzyme in nonaqueous medium is consistent with solvent dependence of its activity, Biophys. J. 87 (2004) 812-821.

[12] F. Secundo, G. Carrea, Lipase activity and conformation in neat organic solvents, J. Mol. Catal. B: Enzymatic, 19-20 (2002) 93-102.

[13] L. F. Garcia-Alles, V. Gotor, Alcohol inhibition and specificity studies of lipase B from Candida antarctica in organic solvents, Biotechnol. Bioeng. 59 (1998) 163-170.

[14] M. Martinelle, K. Hult, Kinetics of acyl transfer reaction in organic media catalysed by Candida antarctica lipase B, Biochim. Biophys. Acta, 1251 (1995) 191-197. 
[15] S. Lamare and M.D. Legoy, Working at controlled water activity in a continuous process: the gas/solid system as a solution, Biotechnol. Bioeng. 45 (1995) 387-397.

[16] S. Lamare, M.D. Legoy and M. Graber M., Solid/gas bioreactors: powerful tools for fundamental research and efficient technology for industrial applications. Green Chem. 6 (2004) 445-458.

[17] M. P. Bousquet-Dubouch, M. Graber, N. Sousa, S. Lamare and M. D. Legoy, Alcoholysis catalysed by Candida antarctica lipase B in a gas/solid system obeys a Ping Pong Bi Bi mechanism with competitive inhibition by the alcohol substrate and water, Biochim. Biophys. Acta, 1550 (2001) 90-99.

[18] M. Graber, M. P. Bousquet-Dubouch, S. Lamare and M.D. Legoy, Alcoholysis catalyzed by Candida antarctica lipase B in a gas/solid system: effects of water on kinetic parameters, Biochim. Biophys. Acta 1648 (2003) 24-32.

[19] Tripos Inc., 1699 South Hanley Rd., St. Louis, Missouri, 63144, USA.

[20] S. J. Weiner, P. A. Kollman, D. A. Case, U. C. Singh, C. Ghio, G. Alagona, S. J. Profeta, P. K. Weiner, A new force field for molecular mechanical simulation of nucleic acids and proteins, J. Am. Chem. Soc. 106 (1984) 765-784.

[21] S. J. Weiner, P. A. Kollman, D. T. Nguyen, D. A. Case, An all atom force field for simulations of proteins and nucleic acid. J. Comput. Chem. 7 (1986) 230-252. 
[22] J. Uppenberg, M.T. Hansen, S. Patkar and T.A. Jones, The sequence, crystal structure determination and refinement of 2 forms of lipase B from Candida antarctica, Structure 4 (1994) 293-308.

[23] H. M. Berman, J. Westbrook, Z. Feng, G. Gilliland, T. N. Bhat, H. Weissig, I. N.

Shindyalov, P. E. Bourne, The protein data bank, Nucleic Acids Res. 28 (2000) 235-242.

[24] S. Raza, L Fransson, K. Hult, Enantioselectivity in Candida antarctica lipase B:

A molecular dynamics study, Protein Sci. 10 (2001) 329-338.

[25] F. Létisse, S. Lamare, M.D. Legoy and M. Graber, Solid/gas biocatalysis : an appropriate tool to study the influence of organic compounds on kinetics of lipase catalyzed alcoholysis. Biochim. Biophys. Acta - Proteins \& Proteomics, 1652 (2003) 27-34. 


\section{Figure legends}

Figure 1. Solvent inhibition effects on enzyme activity. The effect of solvent inhibition on the activity of a transesterification reaction between methyl propanoate and 1-propanol is shown for increasing solvent thermodynamic activities. An inhibitory effect was seen for the solvents 2-pentanone, 3-pentanone and 2-methyl-2-butanol, whereas no significant effect was seen for 2-methylpentane, 3-methylpentane, 2-methyl-2-pentanol and 3-methyl-3-pentanol.

Figure 2. Two-substrate kinetics. The initial rate, $\mathrm{v}_{\mathrm{i}}$, measused in the presence of 2-pentanone, plotted against the thermodynamic activity of methyl propionate $\left(\mathrm{a}_{\mathrm{MP}}\right)$ at different propanol thermodynamic activities $\left(\mathrm{a}_{\mathrm{p}}\right)$. The constant thermodynamic activity of 2-pentanone equals 0.37

Figure 3. Determination of the apparent $V_{\max }$. Reciprocal initial rates plotted versus the reciprocal thermodynamic activity of methyl propanoate in the presence of 2-pentanone. The value of $1 / \mathrm{V}_{\max }$ is given as the ordinate value at $1 / \mathrm{a}_{\mathrm{MP}}=1$. The constant thermodynamic activity of 2-pentanone equals 0.37 .

Figure 4. Determination of inhibition constants of propanol, Ki. The inhibition constant, $\mathrm{K}_{\mathrm{i}}$, of propanol (Scheme 1) in the presence of 2-pentanone, was determined from a re-plot of the reciprocal plot shown in figure 3 . The slopes of the intersecting lines were plotted against the thermodynamic activity of propanol, $a_{p}$. The intersection between the new line $\left(r^{2}=0.96\right)$ and the abscissa equals $-\mathrm{K}_{\mathrm{i}}$. 
Figure 5. Solvent motions in the active site. a) The active site of Candida antarctica lipase B. The catalytic serine (Ser105) and histidine (His224) are shown together with Thr40 and Gln106, which constitutes the oxyanion hole. Trp104 constitutes a "floor" in the active site cavity and is shown both in sticks and in spacefill model. b) Eight hundred sampled and superimposed structures of 2-methyl-2-pentanol in the active site of Candida antarctica lipase B. The alcohol is tightly bound in the active site and remains there during the whole simulation. c) Eight hundred sampled structures of 2-pentanone. The ketone was tightly bound in the active site although other conformations than the oxyanion hole hydrogen bonded ones were also found. The ketone remained in the active site during the whole simulation. d) Eight hundred sampled structures of 2-methyl pentane. There were no attraction between the alkane and the active site, and although the 2-methyl pentane was positioned in the binding site from the start of the simulation, it started exploring the surrounding and found its way out though the active site entrance. 


\section{Scheme 1}<smiles>CCCOC(=O)CC</smiles>

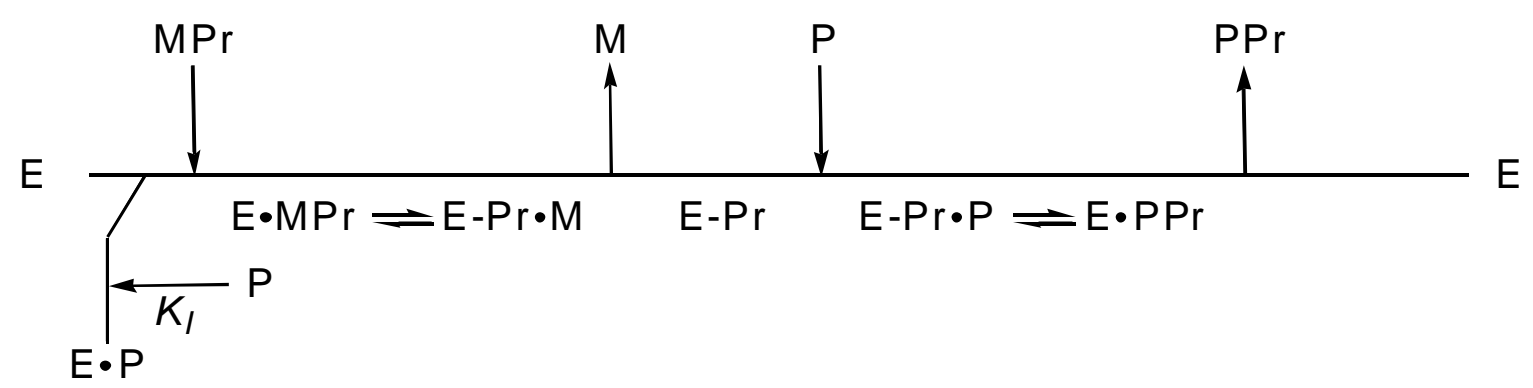

MPr methyl propanoate, M methanol, P propanol, PPr propyl propanoate, E enzyme, '?'denotes noncovalent bond, '-' denotes covalent bond. 


\section{Figure 1}

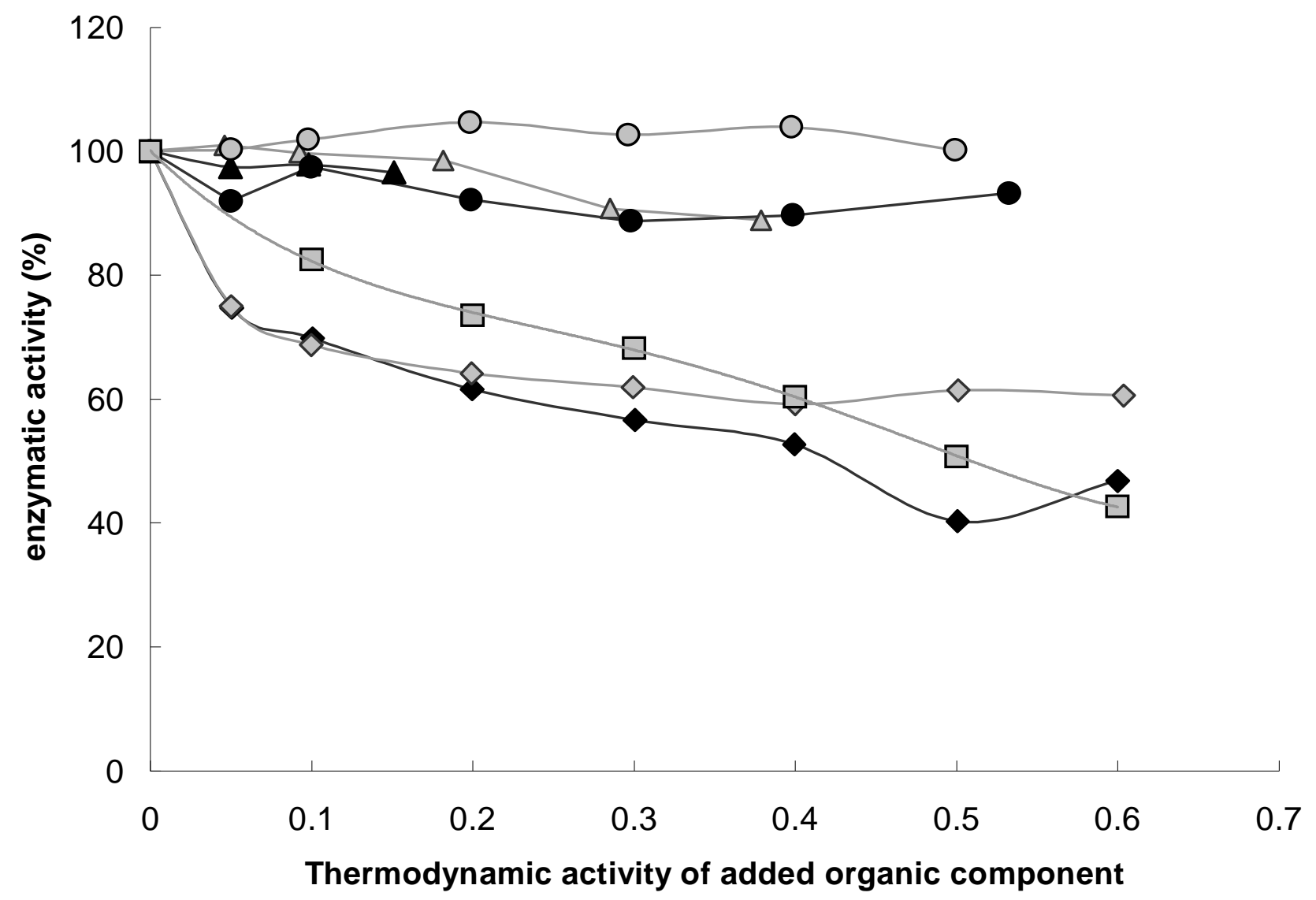

\section{$\multimap 2$-pentanone}

\-2-methylpentane

-2-2-methyl-2-pentanol

ㅁ 2-methyl-2-butanol (results from [25]) $\diamond$ 3-pentanone

$\triangle$ 3-methylpentane

-o-3-methyl-3-pentanol 
Figure 2

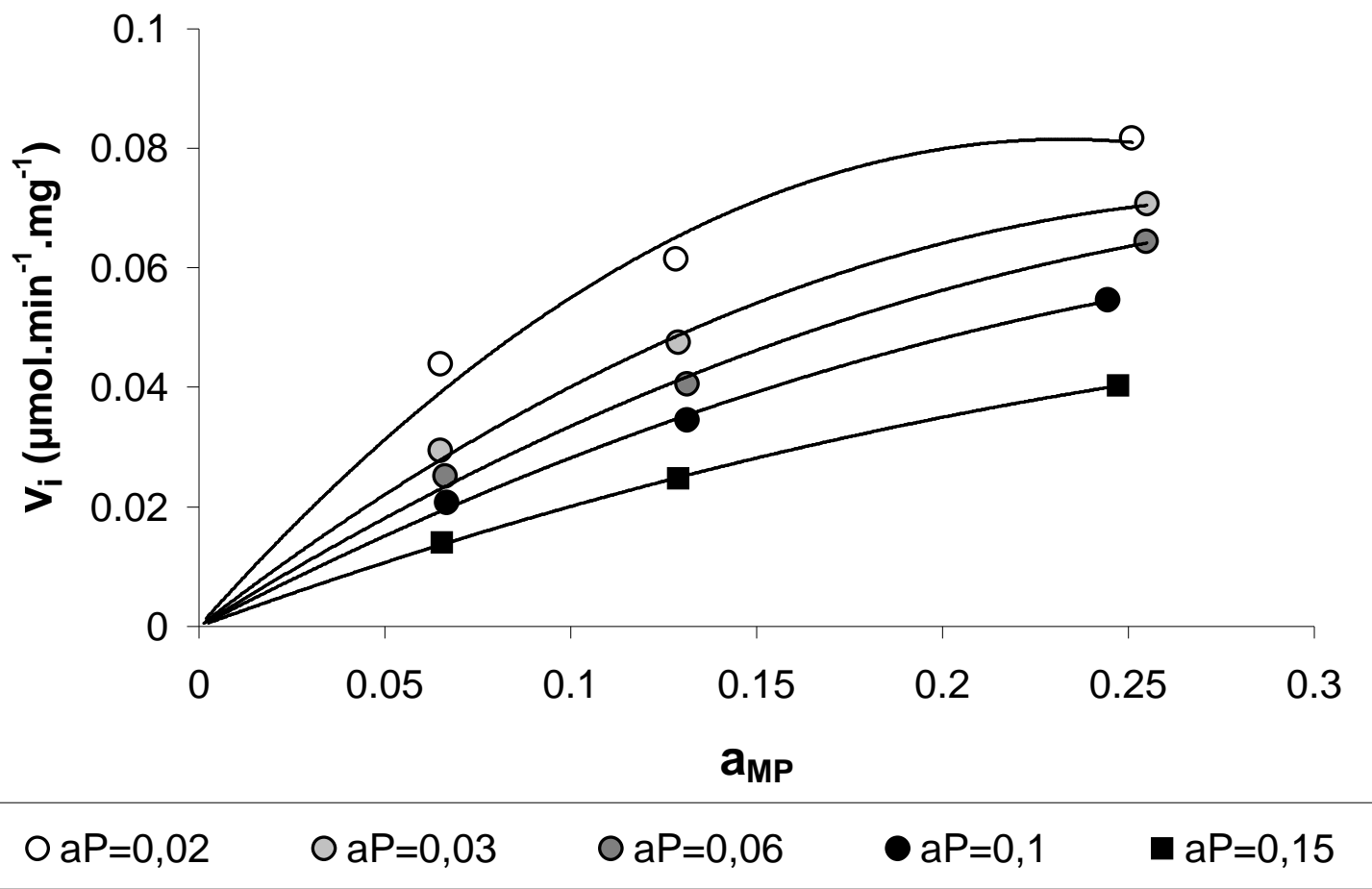




\section{Figure 3}

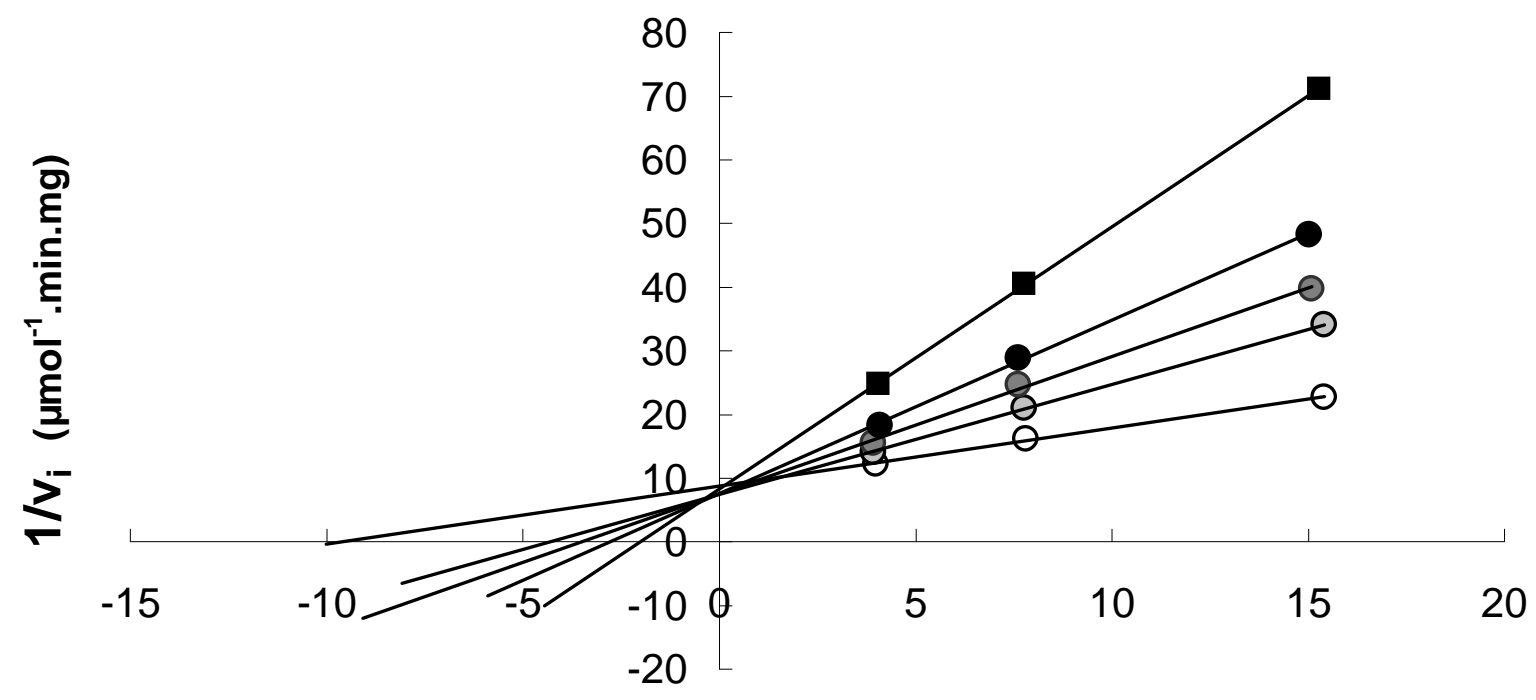

$$
1 / \mathbf{a}_{\mathrm{MP}}
$$

$\mathrm{O} \mathrm{aP}=0,02 \quad \mathrm{O} \mathrm{aP}=0,03 \quad \mathrm{O} \mathrm{aP}=0,06 \quad \bullet \mathrm{aP}=0,1 \quad$ aP $=0,15$

\section{Figure 4}

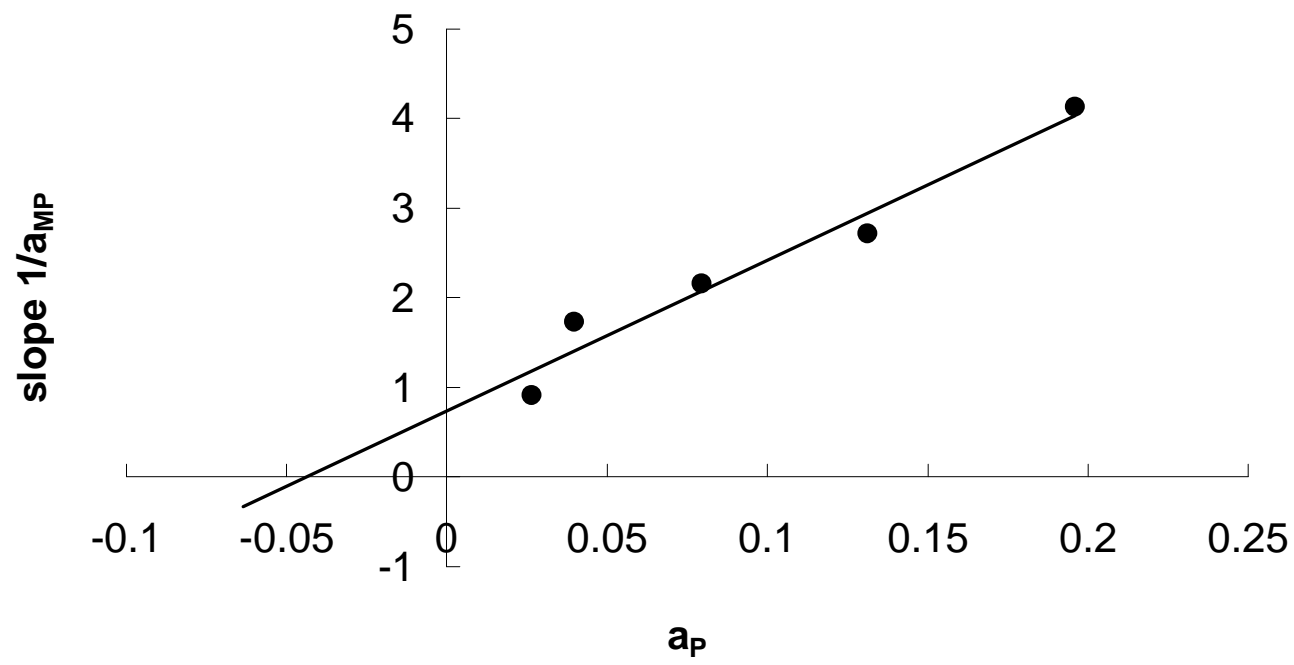




\section{Figure 5}

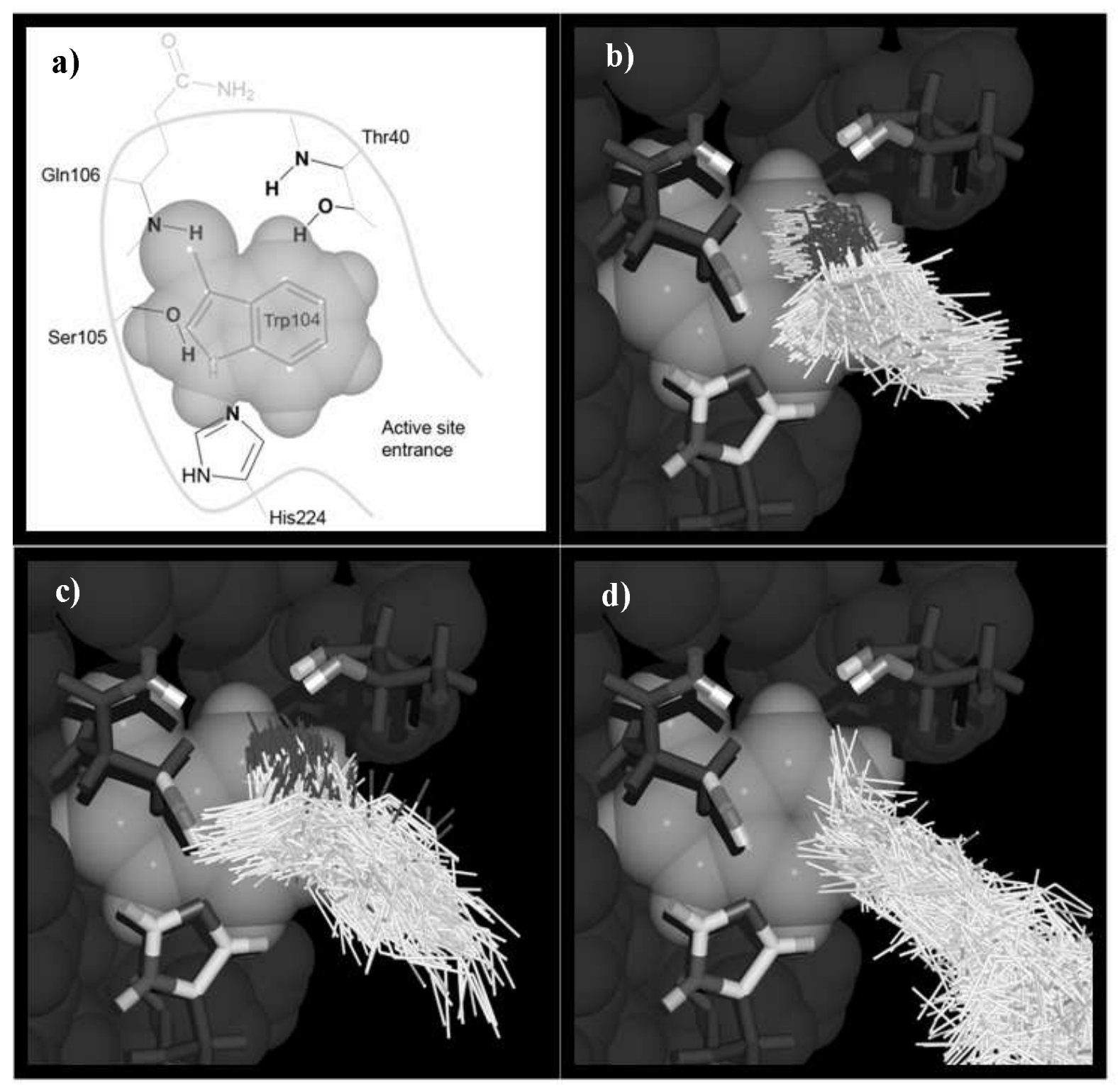

